\title{
Bronchiectasis Economics: Spend Money to Save Money
}

\author{
Pieter C. Goeminne ${ }^{a, b} \quad$ Lowie E.G.W. Vanfleteren ${ }^{c}$ \\ ${ }^{a}$ Department of Respiratory Disease, AZ Nikolaas, Sint-Niklaas, Belgium; ${ }^{\mathrm{b}}$ Department of Respiratory Disease, \\ UZ Leuven, Leuven, Belgium; ' ${ }^{C}$ COPD Center, Sahlgrenska University Hospital, Gothenburg, Sweden
}

Bronchiectasis is a very heterogeneous disease with a large number of possible etiologies and a wide variety of clinical presentations that can range from asymptomatic patients with infrequent exacerbations to patients with daily severe symptoms and recurrent or chronic airway infections and hospitalizations [1]. Logically, the more severe spectrum is what most caregivers see and what research focuses on. What lies beneath is a complex expanse of physical, social, psychological, familial, and economical aspects, which together define the disease status of the individual patient. Recent data suggests that the prevalence and hospitalization rate of bronchiectasis is increasing $[2,3]$. This increased burden of bronchiectasis on healthcare is without doubt associated with increasing economic costs.

Different levels of disease costs can be unraveled. Most data focus on the direct and obvious costs associated with bronchiectatic disease, more specifically, the costs of etiological workup and follow-up, the costs of exacerbations and hospitalizations, and the daily medical costs $[4,5]$. Costs associated with the loss of quality of life and absenteeism as well as the burden put on the family and caregivers, to our knowledge, have not been taken into consideration previously. It is the merit of

\section{KARGER}

(c) 2018 S. Karger AG, Basel

E-Mail karger@karger.com

www.karger.com/res de la Rosa Carrillo et al. [6] that the authors attempt to estimate these costs in this issue of Respiration. de la Rosa Carrillo et al. [6] collected data on employment, salary, the need for sick leave of the patient during the exacerbation, and the need for sick leave of the caregiver [6]. However, the indirect costs due to the loss of productivity seemed to be of little relevance in this study, mainly due to the age distribution. However, even these cost estimates are an underestimation of the real overall bronchiectasis-associated costs as outpatient physiotherapy, rehabilitation programs, home daily medication, insurance, lifestyle adjustment costs (e.g., working part-time due to illness) and comorbidity costs such as anxiety, depression, cardiovascular disease, or other comorbid respiratory conditions are not taken into account. Further research needs to attempt to encompass these financial aspects of bronchiectasis disease.

Due to a combination of an increasing prevalence and high economic costs, research has tried to analyze the factors that influence economic costs. This might then provide a basis upon which tailored interventions can be tested to not only improve bronchiectasis care but simultaneously reduce healthcare costs. As an example, Bedi et al. [7] investigated home intravenous antibiotic treat- 
Fig. 1. Key aspects of bronchiectasis care and research. This patient-centered approach to bronchiectasis care and research considers different factors. This graph depicts some important aspects but does not aim to be exhaustive. The management of bronchiectasis itself and focused research on specific interventions is essential. There is an urgent need to unravel bronchiectasis heterogeneity. A detailed patient characterization is essential to identify new phenotypes and eventually better personalize treatment. With this, the management and understanding of influencing comorbidities are a key factor in both research and care of bronchiectasis patients. This implies that bronchiectasis care is teamwork and implies a multidisciplinary approach including the patient as a specialist of his own life [1]. Such an approach strives for more health per euro. Economic impact analysis of treatments is crucial but needs to be based on the individual patient needs.

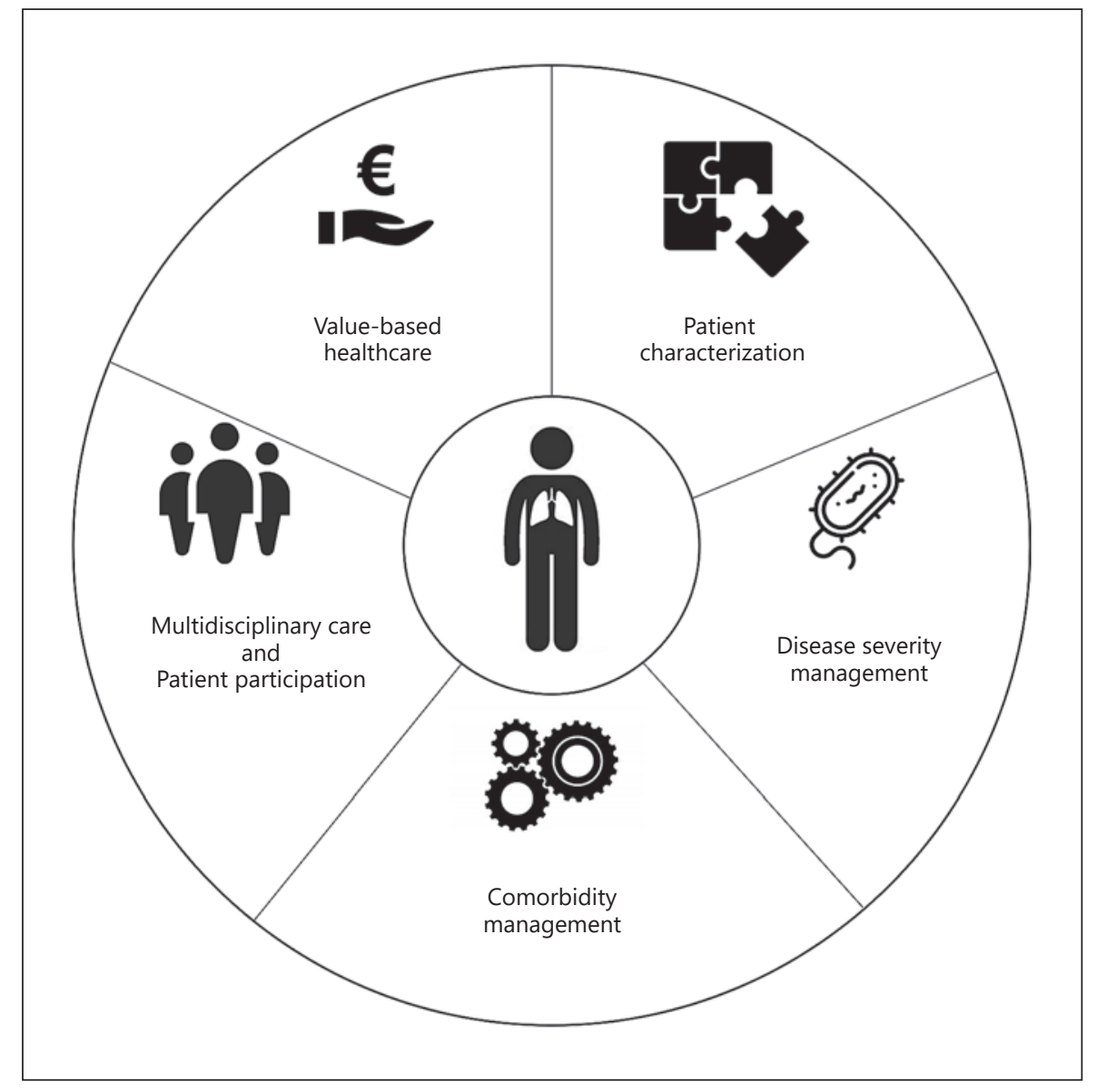

ment in bronchiectasis patients. They showed that this intervention was safe, resulted in less morbidity, was as efficient as hospital-based treatment, and reduced the hospitalization days significantly, thus the healthcare costs.

Through economic analysis, other possible targets for cost reduction can be isolated. Previous research found several factors that augment disease costs in bronchiectasis: decreased $\mathrm{FEV}_{1}$, increased age, a higher number of exacerbations, a higher number of hospital admissions, an increased disease severity measured by FACED, and Pseudomonas aeruginosa infection [8-11]. The latter is now strongly confirmed by de la Rosa Carrillo et al. [6] in this issue of Respiration. They found that patients with chronic bronchial infection by $P$. aeruginosa had more days in the hospital ward, a longer overall hospitalization period, and higher overall costs.

More and more evidence supports the notion that acquisition of $P$. aeruginosa hallmarks a turning point in the disease history of bronchiectasis patients. Recently,
Araújo et al. [12] established that $P$. aeruginosa was independently associated with exacerbation frequency, worse quality of life, and hospital admissions. They also found an increased mortality in the presence of exacerbations. de la Rosa Carrillo et al. [6] explored these costs and found a significant increase in the treatment costs in the few months after hospital discharge due to readmissions and emergency room visits.

All efforts at treating or eradicating $P$. aeruginosa could potentially reduce economic costs. It is essential to find therapeutic strategies that reduce the clinical impact of $P$. aeruginosa without increasing still further the overall healthcare expenses. Many countries are hampered in their daily quality care for patients with bronchiectasis due to the absence of reimbursement for mucoactive agents and inhaled antibiotics [13]. Governmental bodies argue that their costs are too high compared with the solidity of the evidence of their beneficiary effect. This has led to the current tragedy that patients in some countries with severe symptomatic and exacerbating bronchiecta- 
sis have a lack of access to these therapies from which they might importantly benefit. Indeed, the lack of solidity of the evidence as judged by the authorities is most probably influenced by the heterogeneity and the small sample size of the included population in the randomized controlled trials to date [14-16].

Health has been defined as the ability to adapt and manage one's own wellbeing, in light of the physical, emotional, and social challenges in life [17]. Chronic diseases such as bronchiectasis are permanent, as they are caused by irreversible pathological changes. They may be expected to require a long period of supervision, observation, or care. Treatment goals include enhancement of the functional status, minimization of distressing symptoms, and enhancement of the quality of life. These are related to the principles of value-based healthcare, in which value is defined as patient health outcomes per euro spent. In healthcare, the measurement of value should focus on how well the care delivered meets individual patient needs. Indeed, health is a value on itself and it is also a precondition for economic prosperity in a broader sense as health influences productivity, labor supply, human capital, and public spending. Future research should consider both a broad economic outcome analysis but also a broad evaluation of patient health outcomes when testing exacerbation reducing or $P$. aeruginosa-targeting treatments to prove that a treatment that might seem not overwhelmingly beneficial on predefined hard clinical outcomes nonetheless can be considered cost-effective. In addition, related to the complexity of the patient with a chronic disease such as bronchiectasis, these evaluations should also be positioned within the concepts of managed care, which focus on organizing healthcare providers to achieve the dual goal of controlling healthcare costs and managing the quality of care (Fig. 1).

In light of the more recent economic-based decisions in healthcare, bronchiectasis interventions should in our opinion focus on the factors that influence both general bronchiectasis health and costs. This will increase their chance of reimbursement and implementation into daily practice. Taking into consideration all current data, this means that we need to invest more in interventions that try to focus on $P$. aeruginosa control/eradication or exacerbation reduction. The big success of the bronchiectasis registries will undoubtedly cause a surge in successful trials as they will provide a basis to unravel disease heterogeneity, allow larger study populations, and cause better patient selection upon which new interventions focused on $P$. aeruginosa and exacerbations can be performed. In short, we need to spend money to save money $[18,19]$.

\section{References}

1 Polverino E, Goeminne PC, McDonnell MJ, Aliberti S, Marshall SE, Loebinger MR, et al: European Respiratory Society guidelines for the management of adult bronchiectasis. Eur Respir J 2017;50.

2 Quint JK, Millett ER, Joshi M, Navaratnam V, Thomas SL, Hurst JR, et al: Changes in the incidence, prevalence and mortality of bronchiectasis in the UK from 2004 to 2013: a population-based cohort study. Eur Respir J 2016; 47:186-193.

3 Ringshausen FC, de RA, Diel R, Hohmann D, Welte T, Rademacher J: Bronchiectasis in Germany: a population-based estimation of disease prevalence. Eur Respir J 2015;46: 1805-1807.

4 Sanchez-Munoz G, Lopez de Andres A, Jimenez-Garcia R, Carrasco-Garrido P, Hernandez-Barrera $\mathrm{V}$, Pedraza-Serrano $\mathrm{F}, \mathrm{Pu}-$ ente-Maestu L, de Miguel-Diez J: Time trends in hospital admissions for bronchiectasis: analysis of the Spanish National Hospital Discharge Data (2004 to 2013). PLoS One 2016; 11:e0162282.

5 Weycker D, Edelsberg J, Oster G, Tine G: Prevalence and economic burden of bronchiectasis. Clin Pulm Med 2005;12:205-209.
6 de la Rosa Carrillo D, Navarro Rolon A, Girón R, Montull Veiga B, Olveira C, Padilla Galo A, Prados Sánchez C, Quintana Gallego E, Sibila O, Celorrio Jiménez N, Ruiz Peña A, Torres Martí A, Avilés Inglés M, Blanco M, García Clemente M, Golpe R, Gómez Bonilla A, Gómez González C, Leal Arranz M, Minguez Clemente P, López Muñiz B, Máiz L, Pando Sandoval A, Rodríguez Hermosa J, Uranga Echeverria A, Nuñez Ares A, López Roldán L, Abellán Martínez M, Martínez García A, Michel de la Rosa F, Godoy Mayoral R, Martínez-García M: Cost of hospitalizations due to exacerbation in patients with non-cystic fibrosis bronchiectasis. Respiration 2018, DOI: 10.1159/000489935.

7 Bedi $\mathrm{P}$, et al: A prospective cohort study of the use of domiciliary intravenous antibiotics in bronchiectasis. NPJ Prim Care Respir Med 2014;24:14090.

8 de la Rosa D, Martinez-Garcia MA, Olveira C, Giron R, Maiz L, Prados C: Annual direct medical costs of bronchiectasis treatment: Impact of severity, exacerbations, chronic bronchial colonization and chronic obstructive pulmonary disease coexistence. Chron Respir Dis 2016:13:361-371.
9 Blanchette C, Noone J, Stone G, Zacherle E, Runken MC, Howden R, Mapel D: Healthcare cost and utilization before and after diagnosis of pseudomonas aeruginosa among patients with non-cystic fibrosis bronchiectasis in the US. Pneumologie 2016;70:A61.

10 Blanchette C, Noone J, Stone G, Zacherle E, Runken MC, Howden R, Mapel D: Healthcare use and costs among patients with non-cystic fibrosis bronchiectasis in the United States. Am J Respir Crit Care Med 2016;193:A2939.

11 Joish VN, Spilsbury-Cantalupo M, Kamalakar R, Operschall E, Luong B: Direct medical costs associated with exacerbations related to non-cystic fibrosis bronchiectasis. Value Health 2013;16:A188.

12 Araújo D, Shteinberg M, Aliberti S, Goeminne PC, Hill AT, Fardon TC, Obradovic D, Stone G, Trautmann M, Davis A, Dimakou K, Polverino E, De Soyza A, McDonnell MJ, Chalmers JD: The independent contribution of Pseudomonas aeruginosa infection to long-term clinical outcomes in bronchiectasis. Eur Respir J 2018;51. 
13 Goeminne P: From guidelines to real-life data from the EMBARC registry and national audits.1452. European Respiratory Society meeting, Milan, 2017. http://www.ers-education.org/events/international-congress/milan-2017.aspx?idParent $=183975$.

14 Barker AF, O'Donnell AE, Flume P, Thompson PJ, Ruzi JD, de Gracia J, Boersma WG, De Soyza A, Shao L, Zhang J, Haas L, Lewis SA, Leitzinger S, Montgomery AB, McKevitt MT, Gossage D, Quittner AL, O'Riordan TG: Aztreonam for inhalation solution in patients with non-cystic fibrosis bronchiectasis (AIRBX1 and AIR-BX2): two randomised doubleblind, placebo-controlled phase 3 trials. Lancet Respir Med 2014;2:738-749.

15 Aksamit T, De Soyza A, Bandel TJ, Criollo M, Elborn JS, Operschall E, Polverino E, Roth K, Winthrop KL, Wilson R: RESPIRE 2: a phase
III placebo-controlled randomised trial of ciprofloxacin dry powder for inhalation in non-cystic fibrosis bronchiectasis. Eur Respir J 2018;51.

16 Bilton D, Tino G, Barker AF, Chambers DC, De Soyza A, Dupont LJ, O’Dochartaigh C, van Haren EH, Vidal LO, Welte T, Fox HG, Wu J, Charlton B; B-305 Study Investigators: Inhaled mannitol for non-cystic fibrosis bronchiectasis: a randomised, controlled trial. Thorax 2014;69:1073-1079.

17 Huber M, Knottnerus JA, Green L, van der Horst H, Jadad AR, Kromhout D, Leonard B, Lorig K, Loureiro MI, van der Meer JW, Schnabel P, Smith R, van Weel C, Smid H: How should we define health? BMJ 2011;343:d4163.

18 Chalmers JD, Aliberti S, Polverino E, Vendrell M, Crichton M, Loebinger M, Dimakou K, Clifton I, van der Eerden M, Rohde G,
Murris-Espin M, Masefield S, Gerada E, Shteinberg M, Ringshausen F, Haworth C, Boersma W, Rademacher J, Hill AT, Aksamit T, O'Donnell A, Morgan L, Milenkovic B, Tramma L, Neves J, Menendez R, Paggiaro P, Botnaru V, Skrgat S, Wilson R, Goeminne P, De Soyza A, Welte T, Torres A, Elborn JS, Blasi F: The EMBARC European Bronchiectasis Registry: protocol for an international observational study. ERJ Open Res 2016;2.

19 Aksamit TR, O’Donnell AE, Barker A, Olivier KN, Winthrop KL, Daniels MLA, Johnson M, Eden E, Griffith D, Knowles M, Metersky M, Salathe M, Thomashow B, Tino G, Turino G, Carretta B, Daley CL; Bronchiectasis Research Registry Consortium: Adult patients with bronchiectasis: a first look at the US Bronchiectasis Research Registry. Chest 2017; 151:982-992. 